WIDER Working Paper 2017/151

Patterns and trends in horizontal inequality in the Democratic Republic of the Congo

Isaac Kalonda Kanyama*

July 2017

United Nations University World Institute for Development Economics Research

wider.unu.edu 
Abstract: We analyse horizontal inequality in wealth and in years of education in the Democratic Republic of the Congo over the period 2001-13. We find that the trend in horizontal inequality is similar to the trend in vertical inequality over the period of analysis. In addition, horizontal inequality in years of formal education is higher among geographical, gender and linguistic groups, and lower among religious and ethnic groups. More specifically, horizontal inequality between genders is higher among individuals aged 25 years and over compared with the full sample of individuals aged 15 years and over. Based on a regression analysis, we find that household size, economic status and rural residence have a significant effect on gender-based inequality in years of education. We also find that gender-based horizontal inequality in years of education is higher in conflict-affected zones.

Keywords: Democratic Republic of the Congo, economic status, education, ethnicity, horizontal inequality, vertical inequality

JEL classification: D63, D74

Acknowledgements: I acknowledge the support of UNU-WIDER in the achievement of this research. Special thanks to Carla Canelas, to Rachel Gisselquist, and to all the participants at the workshop on 'Group-Based Inequalities: Patterns, Trends Within and Across Countries' held in Helsinki on June 16-17, 2016 for their helpful comments.

* University of Kinshasa, Democratic Republic of the Congo, isaackkanyama@gmail.com

This study has been prepared within the UNU-WIDER project on 'The politics of group-based inequality-measurement, implications, and possibilities for change', which is part of a larger research project on 'Disadvantaged groups and social mobility'.

Copyright C UNU-WIDER 2017

Information and requests: publications@wider.unu.edu

ISSN 1798-7237 ISBN 978-92-9256-377-6 https://doi.org/10.35188/UNU-WIDER/2017/377-6

Typescript prepared by Merl Storr.

The United Nations University World Institute for Development Economics Research provides economic analysis and policy advice with the aim of promoting sustainable and equitable development. The Institute began operations in 1985 in Helsinki, Finland, as the first research and training centre of the United Nations University. Today it is a unique blend of think tank, research institute, and UN agency — providing a range of services from policy advice to governments as well as freely available original research.

The Institute is funded through income from an endowment fund with additional contributions to its work programme from Denmark, Finland, Sweden, and the United Kingdom.

Katajanokanlaituri 6 B, 00160 Helsinki, Finland

The views expressed in this paper are those of the author(s), and do not necessarily reflect the views of the Institute or the United Nations University, nor the programme/project donors. 
This paper aims to analyze group-based inequalities in the Democratic Republic of the Congo (DRC) along geographical, gender, ethnic, religious and linguistic lines. Of particular interest are the investigation of whether the country has been fairer or less fair over time from the group perspective, and the identification of the sources of potential inequality among different subgroups of populations. In addition, we will investigate whether there exists intercleavage inequality that might be a source of potential conflict, and thus of instability.

Such an investigation may be motivated by a twofold argument. First, given the role of both vertical and horizontal inequality in the development of conflict, political instability and economic outcomes (Alesina and Perotti, 1996; Nafziger and Auvinen, 1997, 2002; Collier, 2000; Collier and Hoeffler, 1998; Cramer, 2003; Stewart et. al., 2010), the paper will attempt to identify the aspects of societal structures on which one can act to prevent future developments of conflict in a postconflict country, assuming that recent group inequalities played an important role in the recent conflicts in the DRC. This is important not only for post-conflict recovery, but also for any country in quest of fairness. Second, the evaluation of the extent of and trend in horizontal inequality will help to give a clear orientation to post-conflict recovery plans and to design policies that reliably lead to the achievement of sustainable development goals.

However, reaching sustainable development goals cannot be envisioned without proper consideration of the salient characteristics of the society in question, especially in an ethnically and linguistically diversified country such as the DRC. In particular, ethnicity-understood as any socially significant division of individuals in a society according to clearly defined characteristicsaffects important aspects of the development process, and can seriously impede that process when people's access to current and future life-empowering opportunities is constrained by their ethnic membership. A common result is that ethnic diversity is a crucial cause of poverty and instability (Kaplan, 1984; Easterly and Levine, 1997), which has destructive effects on civil society and morale (Davidson, 1992) in Africa and interacts fairly extensively with class divisions in a country. It is arguable that dealing with ethnicity in Africa is crucial before we deal with problems such as political misrule, poverty and human misery (Noyoo, 2000).

In the specific case of the DRC, ethnicity as well as class plays an important role in the acquisition, maintenance and distribution of wealth, prestige and political power (Schatzberg, 1981). Thus ethnicity in all its forms is an important characteristic of the social landscape of the country. Therefore, measuring group-based inequality has important policy implications. However, there exist a very limited number of studies on either vertical or horizontal inequality in the DRC.

Among the rare papers in the literature, Moummi (2010) and Ortiz and Cummins (2011) analyze vertical inequality in the DRC and find that inequality considerably increased between 2005 and 2007. For example, the estimated Gini coefficient was 0.39 in 2005 at the national level, 0.38 in urban areas and 0.36 in rural areas. Regional disparities were characterized by higher inequality in the capital city, Kinshasa, with a Gini coefficient of 0.40, while some of the 10 provinces had relatively low levels. The Theil index was estimated at 0.32 nationwide, 0.31 in urban areas and 0.21 in rural areas. The estimated Gini coefficient was 0.422 in 2007.

Shapiro and Tambashe (1999) analyze the impact of poverty on gender differences in school enrollment rates of youth aged six to 25 . The main finding is that while increased economic wellbeing is associated with higher enrollment rates for females and males, improved economic status does not translate into reduced gender differences in school outcomes. They argue that gender 
differences in enrollment are relatively modest among the poorest households and tend to be widest in the next segment of the population. However, this analysis is limited in terms of geographical coverage as well as in terms of salient groups such as ethnic, religious and communal cleavages. In addition, the focus is on differences in school enrollment, rather than wealth and educational achievement in terms of years of formal education. Our paper, although restricted to individuals aged 15 and above, has a national and larger time coverage with a focus on inequalities in wealth and education. As such, it makes a major contribution to the understanding of the extent of horizontal inequality in the DRC over time.

We find that horizontal inequality in both wealth (economic status) and years of formal education follows the same trend as that observed in vertical inequality. On the one hand, horizontal inequality in wealth is higher among geographical areas, and lower among religious and ethnic groups. On the other hand, geographical-, gender- and language-based inequalities in years of education are higher than religion- and ethnic-based inequalities. It shall be noted in particular that gender-based horizontal inequality is higher among the population aged 25 and above than in the full sample, which includes individuals aged 15 and above. Finally, our regression analysis reveals that household size, residence (urban or rural) and wealth significantly explain the observed gender-based horizontal inequality in years of education. More specifically, an additional household member above the average household size increases gender-based horizontal inequality in education by between 0.019 and 0.038 percentage points, while an improvement in wealth leads to a decrease in horizontal inequality by between 0.046 and 0.114 percentage points. We also find a significant effect of conflict on gender-based horizontal inequality in years of education. In particular, conflict-affected zones have higher levels of inequality than non-affected zones.

The remainder of the paper is organized as follows. Section 2 describes the source of the data as well as the variables used in the analysis. Section 3 is devoted to the analysis of the extent of and trends in horizontal inequality with respect to different cleavages. The effect of conflict on groupbased inequality is considered in Section 4, and the conclusion of the paper is provided in Section 5.

\section{Description of the data}

This section is devoted to the presentation of the data used in the analysis, and provides some important descriptive statistics as well as a description of the educational system in the DRC.

\subsection{Source of the data}

The analysis of horizontal inequality faces major challenges in terms of data. This is particularly true for the DRC, since one common source of data, the census, is unreliable. The only representative census that has ever been conducted was in 1984, and its various measures are currently considered obsolete and are not recommended as a reference for reliably planning and monitoring development. ${ }^{1}$ Thus we use nationwide and representative surveys for up to five years of data between 2001 and 2013: the Multiple Indicators Cluster Surveys (2001 and 2010), the Demographic and Health Surveys (2007 and 2013) and the Consumption and Expenditure Surveys (2005).

\footnotetext{
${ }^{1}$ http:/ /ins-rdc.org/?q=content/deuxieme-recensement-general-de-la-population-et-de-1\%E2\%80\%99habitat
} 
We consider measures of group inequality in two socio-economic variables, namely wealth and years of formal education, along ethnic, religious, linguistic, regional, gender and geographical lines. To ensure comparability over time and among surveys, we constructed our own wealth index based on a common list of assets. The wealth index is built through factor analysis, using the first component as weights, following authors such as Sahn and Stifel (2000).

\subsection{Descriptive statistics}

We provide some descriptive statistics on ethnicity and education in Tables 1 and 2, based on the survey data. Table 1 shows that Christianity is the dominant religion in the DRC, and that more than $52 \%$ of the population lives in rural areas. The country's majority population is Bantu, among whom the dominant tribes are the Luba (18\%), the Mongo (17\%) and the Kongo (12\%). However, it is important to note that, since we are not using census data, changes in various proportions of the population do not reflect real changes in population composition over time.

Table 1: Population by diversity variables

\begin{tabular}{llcccc}
\hline Diversity variable & Grouping & 2005 & 2007 & 2010 & 2013 \\
\hline \multirow{2}{*}{ Ethnic group } & Bantu & & & & \\
& Others & & 99.53 & 93.82 & 99.51 \\
Gender & Female & & 0.47 & 6.18 & 0.49 \\
& Male & 51.49 & 55.78 & 51.06 & 53.13 \\
Place of residence & Rural & 48.51 & 44.22 & 48.94 & 46.87 \\
& Urban & & & & \\
Religion & & 54.28 & 52.76 & 56.99 & 65.36 \\
& Christianity & 45.72 & 47.24 & 43.01 & 34.64 \\
& Islam & 86.56 & 91.14 & 84.28 & 91.93 \\
& Kimbaguism & 1.54 & 2.41 & 2.74 & 0.18 \\
& Animism & 3.09 & 3.58 & 3.29 & 3.15 \\
& Other religions & 0.41 & 0.63 & 1.09 & 0.55 \\
& No religion & 1.65 & 0.25 & 6.61 & 1.26 \\
Language & National dialects & 9.75 & 1.99 & 1.99 & 1.31 \\
& Others & & & & \\
\hline
\end{tabular}

Source: author's compilation.

Table 2: Percentage of population by level and years of education

\begin{tabular}{llccc}
\hline & & 2007 & 2010 & 2013 \\
\hline Non-formal education & & 19.75 & 17.07 & 15.86 \\
Some primary education & 27.68 & 26.35 & 25.14 \\
Completed primary and some secondary school & 40.51 & 42.25 & 43.66 \\
Completed secondary school & & 7.87 & 8.99 & 10.63 \\
Some university education & & 3.38 & 2.20 & 3.66 \\
University degree and above & Full sample & 0.80 & 3.14 & 1.05 \\
& Educated & 6.43 & 7.67 & 6.55 \\
Years of education (pop. 15+) & Full sample & 6.06 & 7.73 & 7.81 \\
& Educated & 8.74 & 7.98 & 6.22 \\
Years of education (pop. 25+) & & & 8.05 & 7.86 \\
\hline
\end{tabular}

Source: author's compilation. 


\subsection{The educational system in the DRC}

The educational system in the DRC is managed at three main levels: central government, the regions, and educational institutions. The central government is responsible for general educational policy, with responsibility shared between two ministries: the Ministry of Primary, Secondary and Professional Education and the Ministry of Higher Education. At the regional level, the governor of each province is in charge of the administrative supervision of structures that represent the central government with regard to educational matters. There are four main levels: primary (six years), secondary (six years), university (five years) and post-university (four to seven years). The theoretical age ranges for the first three levels are respectively six to 11 years, 12 to 17 years, and 18 to $20 / 22$ years.

We present information on educational attainment as well as the average years of formal education in 2007, 2010 and 2013. Table 2 shows that the proportion of the non-educated population decreased from about $20 \%$ in 2007 to about $16 \%$ in 2013, and that the proportion of the population with completed primary education and some secondary education is above $40 \%$ and has been increasing since 2007. The proportion of educated people with secondary education and above is less than $15 \%$. Average years of education are presented for individuals aged 15 years and above, and then for those aged 25 years and above.

\section{Trends in horizontal inequality}

\subsection{Overview of trends in vertical inequality}

In this section we discuss our main results on inequality over time and across socially salient identified groups. We start by presenting measures of vertical inequality for the years considered in this paper in order to compare the trend in horizontal inequality to that observed in vertical inequality. Table 3 presents three measures of vertical inequality in years of education-namely the coefficient of variation (COV), the Gini coefficient (GINI) and the Theil index (THEIL) and in wealth based on different surveys.

Table 3: Measures of vertical inequality (2003-2013)

\begin{tabular}{lcccccc}
\hline \multirow{2}{*}{ Year } & \multicolumn{3}{c}{ Years of education } & \multicolumn{3}{c}{ Wealth } \\
& COV & GINI & THEIL & COV & GINI & THEIL \\
\hline 2001 & & & & & & 0.7248 \\
2005 & 0.5347 & 0.3040 & 0.1607 & 1.3241 & 0.6394 & 0.4324 \\
2007 & 0.6962 & 0.3970 & 0.3768 & 1.0124 & 0.5102 & 0.2522 \\
2010 & 1.3210 & 0.4705 & 0.6199 & 0.7562 & 0.3935 & 0.2733 \\
2013 & 0.6406 & 0.2840 & 0.1531 & 0.7827 & 0.4113 & 0.4079 \\
Variation (2001-2007) \% & 0.8002 & 0.3922 & 0.3757 & 1.0101 & 0.49 .9 & -64.2 \\
Variation (2007-2013) \% & +147 & +54.8 & +286 & -42.9 & -38.5 & +61.7 \\
\hline
\end{tabular}

Source: author's computation.

Table 3 and Figure 1 show that the trend in vertical inequality (VI) differs for years of education and wealth. Panel (a) of Figure 1 shows that vertical inequality in education increased from 2001 to 2007 before decreasing subsequently until 2010 and then increasing from 2010 to 2013. In contrast, it can be seen from Panel (b) that vertical inequality in wealth decreased from 2001 to 2007 and then increased thereafter. Table 3 also shows the percentage change in each measure of vertical inequality for the subperiods 2001-2007 and 2007-2013. 


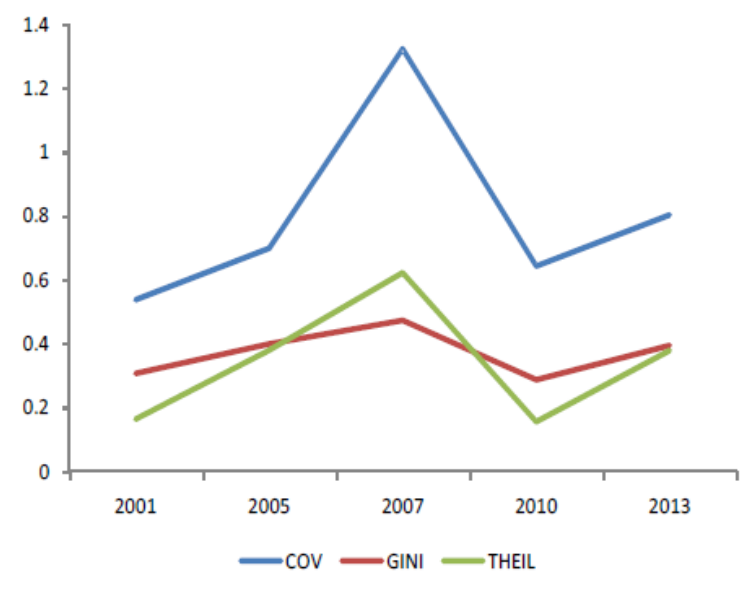

(a) VI in years of education

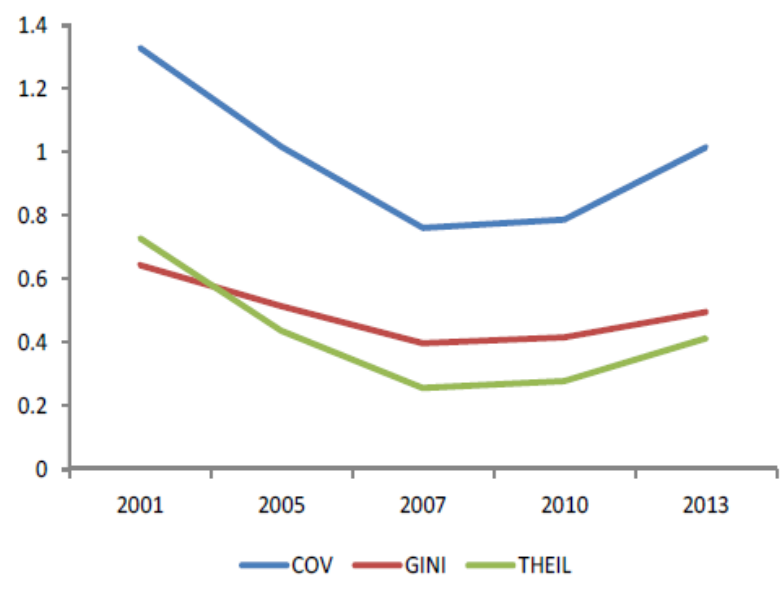

(b) VI in wealth

Source: author's computation.

\subsection{Trends in horizontal inequality}

The objective pursued in this section is to evaluate horizontal inequality along the ethnic lines previously identified, and then to compare its trend with that of vertical inequality. For each of these ethnic cleavages, inequality is measured using the three indicators suggested by Stewart et al. (2010), that is, the group-weighted Gini coefficient (GGINI), the group-weighted Theil (GTHEIL) and the group-weighted coefficient of variation (GCOV). These indicators are supplemented by the measures of cross-cuttingness and cross-fractionalization suggested by Selway (2011). We present trends in horizontal inequality first in economic status and then in years of education.

Table 4 shows higher horizontal inequality in wealth across geographical areas, namely across regions and between rural and urban residents. For both cleavages, horizontal inequality decreased from 2001 but was on rise at the end of the period of analysis. Horizontal inequality between urban and rural areas decreased until 2007 and increased thereafter, with the highest surge observed between 2010 and 2013. In contrast, horizontal inequality among regions decreased until 2010 and increased between 2010 and 2013. It can also be seen from Table 4 that the levels of horizontal inequality are lowest across ethnic, linguistic and religious groups, although these do not depict a common trend. 
Table 4: Trends in horizontal inequality in wealth

\begin{tabular}{|c|c|c|c|c|c|c|}
\hline Indicator & Year & Ethnicity & Urban/rural & Religion & Region & Language \\
\hline \multirow[t]{5}{*}{ GCOV } & 2001 & & 0.970 & & 0.960 & \\
\hline & 2005 & & 0.651 & 0.136 & 0.770 & 0.239 \\
\hline & 2007 & 0.078 & 0.540 & 0.080 & 0.537 & \\
\hline & 2010 & 0.132 & 0.566 & 0.082 & 0.500 & 0.472 \\
\hline & 2013 & 0.091 & 0.721 & 0.137 & 0.702 & \\
\hline \multirow[t]{5}{*}{ GGINI } & 2001 & & 0.473 & & 0.444 & \\
\hline & 2005 & & 0.324 & 0.011 & 0.368 & 0.045 \\
\hline & 2007 & 0.001 & 0.269 & 0.019 & 0.253 & \\
\hline & 2010 & 0.027 & 0.280 & 0.017 & 0.227 & 0.136 \\
\hline & 2013 & 0.000 & 0.343 & 0.016 & 0.301 & \\
\hline \multirow[t]{5}{*}{ GTHEIL } & 2001 & & 0.510 & & 0.366 & \\
\hline & 2005 & & 0.092 & 0.060 & 0.105 & 0.065 \\
\hline & 2007 & 0.035 & 0.080 & 0.018 & 0.052 & \\
\hline & 2010 & 0.033 & 0.082 & 0.027 & 0.044 & 0.203 \\
\hline & 2013 & 0.041 & 0.111 & 0.056 & 0.074 & \\
\hline
\end{tabular}

Source: author's computation.

Next we analyze horizontal inequality in education, as measured by years of formal schooling, for respondents aged 15 and above (Table 5) and for respondents aged 25 and above (Table 6). The calculated values of GCOV, GGINI and GTHEIL indicate higher horizontal inequality across geographical areas, namely across regions, between rural and urban areas, and between the capital city and other areas of the country. Group-based inequality between males and females is also high, but the lowest levels of inequality are observed among ethnic, linguistic and religious groups. As far as education as a continuous variable is concerned, the observed trend in horizontal inequality is the same for all groups, and is similar to that in vertical inequality (see Table 3). More precisely, the observed levels of horizontal inequality evolve in three phases: a decrease from 2001 to 2007, a decrease between 2007 and 2010, and then an increase between 2010 and 2013. In general, inequality levels across groups are higher among respondents aged 25 and above than among respondents in the whole sample, which includes individuals aged 15 and above.

Table 5: Measures of horizontal inequality in education (age 15+ years)

\begin{tabular}{|c|c|c|c|c|c|c|c|c|}
\hline & Year & $\begin{array}{l}\text { Ethnic } \\
\text { groups }\end{array}$ & Language & Religion & Region & Gender & $\begin{array}{l}\text { Rural/ } \\
\text { urban }\end{array}$ & $\begin{array}{c}\text { Capital/ } \\
\text { others }\end{array}$ \\
\hline \multirow[t]{5}{*}{ GCOV } & 2001 & & & & 0.202 & 0.100 & 0.224 & 0.230 \\
\hline & 2005 & & 0.144 & 0.020 & 0.221 & 0.208 & 0.271 & 0.250 \\
\hline & 2007 & 0.044 & & 0.072 & 0.292 & 0.209 & 0.332 & 0.393 \\
\hline & 2010 & 0.058 & 0.143 & 0.036 & 0.132 & 0.114 & 0.200 & 0.217 \\
\hline & 2013 & 0.027 & & 0.075 & 0.228 & 0.221 & 0.281 & 0.397 \\
\hline \multirow[t]{5}{*}{ GGINI } & 2001 & & & & 0.101 & 0.050 & 0.106 & 0.058 \\
\hline & 2005 & & 0.029 & 0.004 & 0.123 & 0.104 & 0.132 & 0.075 \\
\hline & 2007 & 0.001 & & 0.011 & 0.142 & 0.102 & 0.166 & 0.105 \\
\hline & 2010 & 0.014 & 0.062 & 0.007 & 0.058 & 0.057 & 0.099 & 0.038 \\
\hline & 2013 & 0.001 & & 0.009 & 0.104 & 0.110 & 0.134 & 0.081 \\
\hline \multirow[t]{5}{*}{ GTHEIL } & 2001 & & & & -0.033 & -0.007 & -0.025 & 0.222 \\
\hline & 2005 & & 0.003 & 0.000 & 0.015 & 0.022 & 0.017 & 0.224 \\
\hline & 2007 & 0.019 & & 0.024 & 0.017 & 0.028 & 0.032 & 0.169 \\
\hline & 2010 & 0.008 & 0.025 & 0.009 & 0.001 & 0.007 & 0.004 & 0.096 \\
\hline & 2013 & 0.009 & & 0.029 & 0.010 & 0.020 & 0.020 & 0.182 \\
\hline
\end{tabular}

Source: author's computation. 
Table 6: Measures of horizontal inequality in education (age 25+ years)

\begin{tabular}{|c|c|c|c|c|c|c|c|c|}
\hline & Year & $\begin{array}{l}\text { Ethnic } \\
\text { groups }\end{array}$ & Language & Religion & Region & Gender & $\begin{array}{l}\text { Rural/ } \\
\text { urban }\end{array}$ & $\begin{array}{c}\text { Capital/ } \\
\text { others }\end{array}$ \\
\hline \multirow[t]{5}{*}{$\overline{\mathrm{GCOV}}$} & 2001 & & & & 0.250 & 0.135 & 0.229 & 0.232 \\
\hline & 2005 & & 0.161 & 0.020 & 0.251 & 0.249 & 0.280 & 0.250 \\
\hline & 2007 & 0.052 & & 0.079 & 0.332 & 0.274 & 0.375 & 0.488 \\
\hline & 2010 & 0.057 & 0.159 & 0.042 & 0.136 & 0.148 & 0.214 & 0.234 \\
\hline & 2013 & 0.032 & & 0.074 & 0.264 & 0.291 & 0.318 & 0.468 \\
\hline \multirow[t]{5}{*}{ GGINI } & 2001 & & & & 0.102 & 0.067 & 0.108 & 0.060 \\
\hline & 2005 & & 0.032 & 0.004 & 0.130 & 0.124 & 0.139 & 0.075 \\
\hline & 2007 & 0.001 & & 0.011 & 0.165 & 0.134 & 0.192 & 0.126 \\
\hline & 2010 & 0.014 & 0.069 & 0.008 & 0.060 & 0.074 & 0.106 & 0.037 \\
\hline & 2013 & 0.002 & & 0.010 & 0.119 & 0.145 & 0.150 & 0.098 \\
\hline \multirow[t]{5}{*}{ GTHEIL } & 2001 & & & & -0.039 & -0.013 & -0.030 & 0.224 \\
\hline & 2005 & & 0.005 & -0.000 & -0.008 & 0.031 & 0.014 & 0.224 \\
\hline & 2007 & 0.022 & & 0.070 & 0.093 & 0.131 & 0.138 & 0.538 \\
\hline & 2010 & 0.008 & 0.004 & 0.009 & 0.001 & 0.006 & 0.004 & 0.106 \\
\hline & 2013 & 0.011 & & -0.025 & 0.013 & 0.029 & 0.025 & 0.220 \\
\hline
\end{tabular}

Source: author's computation.

The observed inequality in years of formal education between males and females is mainly explained by factors such as early marriage of girls and the financial deprivation of most households (INS, 2014). For example, about $12 \%$ and $11 \%$ of women were married before 15 years in 2007 and 2010 respectively. Generally, early marriage is accompanied by the termination of school attendance. This phenomenon is more prominent in rural than urban areas, and thus explains a significant proportion of the geographical disparities in the average years of education.

\subsection{Sources of horizontal inequality}

Table 7 summarizes the decomposition of horizontal inequality in years of education into a component due to characteristics that are specific to each group (within-group inequality) and a component that is due to differences between groups (between-group inequality) based on gender and geographical areas. The decomposition is achieved on the basis of the GTHEIL coefficient, which satisfies the decomposability property. As it turns out, the proportion of horizontal inequality due to characteristics that are gender-specific increased between 2007 and 2013. For individuals aged 15 years and above, this proportion increased from about $70 \%$ to $93 \%$, while it increased from $62 \%$ to $93 \%$ for individuals aged 25 and above. Table 7 also shows that at least $30 \%$ of the increased horizontal inequality is explained by differences between men and women.

Table 7: Percentage of within-group inequality

\begin{tabular}{lcccc}
\hline Age range & Year & Gender & Urban/rural & Region \\
\hline 15 years and more & 2007 & 69.7 & 72.4 & 67.5 \\
& 2013 & 92.6 & 36.3 & 32.9 \\
& Change (\%) & +22.9 & $-\mathbf{3 6 . 3}$ & $\mathbf{- 3 1 . 6}$ \\
25 years and more & & & & 41.1 \\
& 2007 & 62.9 & 82.6 & 33.4 \\
& 2013 & 93.3 & 35.5 & $\mathbf{- 7 . 7 0}$ \\
\hline
\end{tabular}

Source: author's computation.

The proportion of horizontal inequality based on geographical areas (urban/rural, region) that is explained by group-specific factors declined between 2007 and 2013, in contrast with the trend in 
gender-based horizontal inequality. This implies that the observed inequality in years of education is increasingly explained by differences between rural populations and urban populations, as well as differences among different regions of the country.

\subsection{Cross-cuttingness and cross-fractionalization}

In the above sections we analyzed group-based inequality along ethnolinguistic, religious and linguistic lines. We were then able to decompose the sources of the observed group inequality accordingly, especially horizontal inequality in years of education as far as gender and geographical areas were concerned. However, the results obtained cannot help us to answer questions about intergroup inequality and the possibility of conflict onset. To be able to do so, we analyze the measures of cross-cuttingness and cross-fractionalization recently developed in the literature in conjunction with the study of horizontal inequality (Selway, 2011; Gubler and Selway, 2012). Following Gubler and Selway (2012), we maintain that the probability of the onset of civil war is lower when the ethnic cleavage in a society is cross-cut with other salient cleavages in that society, namely geography, socio-economic status and religion. Indeed, these three factors have been attributed with the potential for conflict onset in the literature (Matuszeski and Schneider, 2006; Collier and Hoeffler, 2004; Humphreys and Weinstein, 2008; Stewart, 2000; Stewart et al., 2010). The main point is that higher cuttingness of the ethnic cleavage with the three other salient cleavages creates a context that is unfavorable to the onset of civil war, decreasing its likelihood even in societies with other favorable conditions (Gubler and Selway, 2012), and thus leading to a more stable society and less interethnic inequality. Thus higher cross-cuttingness promotes social and political stability that is favorable for investment and economic growth.

We present the measures of ethno-religious, ethno-geographical and ethno-economic cuttingness in Table 8. The measure of ethno-economic cuttingness was calculated with respect to the wealth level of the respondents, based on wealth distribution rather than income distribution. Measures of cross-cuttingness were obtained as averages based on the Demographic and Health Survey datasets to ascertain the homogeneity of the data used. It turns out that although the DRC is not a perfect cross-cuttingness country, it is characterized by quite a high degree of cuttingness, suggesting lower interethnic inequalities. It is important to observe that all the measures of crosscuttingness involving ethnic groups are higher than 0.85 . On the other hand, there is lower crosscuttingness with regard to educational attainment and gender, educational attainment and economic status, and educational attainment and geographical areas (urban/rural), suggesting the existence of some extent of intergroup inequality along these cross-cleavages. Here, educational attainment is measured in terms of a six-point scale $(0=$ no formal education; $1=$ some primary schooling; 2 = completion of primary school and some secondary schooling; $3=$ completion of secondary school; 4 = some tertiary education; $5=$ university degree or above). Measures of crossfractionalization globally show that there is no evidence of reinforcement of one cleavage. 
Table 8: Measures of ethnic diversity

\begin{tabular}{llllll}
\hline Cross-cleavage & & 2007 & 2013 & Average & Change \\
\hline Ethnicity/religion & CC & 0.865 & 0.877 & 0.871 & +0.012 \\
& CF & 0.171 & 0.161 & 0.166 & -0.010 \\
Ethnicity/wealth & CC & 0.930 & 0.924 & 0.927 & -0.006 \\
& CF & 0.971 & 0.793 & 0.792 & +0.002 \\
Ethnicity/educ. attain. & CC & 0.937 & 0.907 & 0.922 & -0.030 \\
& CF & 0.764 & 0.776 & 0.770 & +0.012 \\
Religion/wealth & & & & & \\
& CC & 0.765 & 0.877 & 0.821 & +0.112 \\
Religion/educ. attain. & CF & 0.694 & 0.606 & 0.650 & -0.088 \\
& CC & 0.824 & 0.825 & 0.825 & +0.001 \\
Wealth/educ. attain. & CF & 0.338 & 0.676 & 0.507 & +0.338 \\
& CC & 0.502 & 0.477 & 0.490 & -0.025 \\
& CF & 0.338 & 0.101 & 0.220 & -0.237 \\
\hline
\end{tabular}

Source: author's computation.

\subsection{Measures of ethnic diversity}

Understanding ethnic diversity in a society is important, since a highly diversified society may be prone to tension that can create social instability and lead to conflict. In addition, high ethnic diversity generates undesirable outcomes such as low economic growth (Easterly and Levine, 1997), high levels of corruption (Mauro, 1995), low social cohesion and low contribution to local public goods (Alesina et. al., 1999). Thus lower levels of ethnic diversity are desirable. Two measures of ethnic diversity are considered in this paper, namely ethnic fractionalization (Taylor and Hudson, 1972) and ethnic polarization (Montalvo and Reynal-Querol, 2005, 2008). While measures of ethnic fractionalization are appropriate for determining the probability that two randomly drawn individuals in a society belong to different ethnic groups, measures of ethnic polarization are more intended to capture the intensity of disagreement across ethnic groups (Alesina et al., 2003).

The indices of ethnic fractionalization and ethnic polarization were obtained using the 2007 and 2013 Demographic and Health Survey datasets. We calculated each index for each year, and then considered the average as our index of ethnic diversity. The calculated polarization index was 0.787 in 2007 and 0.759 in 2013, while the values of the fractionalization index were 0.819 in 2007 and 0.842 in 2013 . We thus obtain a measure of polarization of 0.773 and a measure of ethnic fractionalization of 0.831 over the considered period. These values are quite high, and convey the idea of a highly ethically diversified society. It is important to mention that the measure of ethnic fractionalization obtained in this paper is comparable with the value of 0.875 obtained by Alesina et al. (2003) for the DRC.

\section{The effect of conflict}

The literature sufficiently documents the relationship between conflict and inequality, both vertical and horizontal. One strand of the literature argues that vertical inequality in national income distribution, as measured by the Gini coefficient, is a strong predictor of political instability and conflict (Alesina and Perotti, 1996; Nafziger and Auvinen, 1997, 2002), and that national income 
distribution is far more significant in causing conflict than factors such as land distribution (Muller and Seligson, 1987). However, a consideration of vertical inequality alongside other factors such as income per capita, natural resource endowment and ethnolinguistic fragmentation leads to contrasting conclusions as to the role played by inequalities in causing conflict. In particular, inequality is inversely correlated with conflict, as inequality significantly reduces the risk and duration of war (Collier and Hoeffler, 1996, 1998). Thus inequality is bad for and makes no significant contribution to conflict (Collier, 2000). In addition, the empirical findings on the causal link from vertical inequality to conflict have been disputed in light of both cross-sectional data (Fearon and Laitin, 2003) and historical data (Cramer, 2003). An interesting implication of this analysis is that it may well be true that inequality produces conflict and often violence, but this need not attain the scale of civil war (Cramer, 2003).

The relation between horizontal inequality and conflict has been explored as well. Independently of vertical inequality, increasing group inequality is an important source of grievance that leads to conflict (Stewart, 2000, 2002; Murshed and Gates, 2005; Stewart et al., 2010). In particular, group inequality affects the well-being of group members, and the relative impoverishment of the group increases its members' perception that they are likely to be trapped permanently in a poor position - a perception that is more likely to trigger conflict. From this perspective it is important to identify the cleavages that are more likely to generate conflict. In this regard, ethnicity has received particular interest in many studies. For example, Robinson (2001) argues that ethnic conflict tends to increase as intergroup inequality increases, although such inequality is not immediately deduced from socio-economic inequality as usually measured. However, Esteban and Ray $(1999,2008)$ argue that polarization as a measure of interpersonal antagonism matters more than inequality in explaining the emergence and intensity of conflict.

It is important to note that none of the aforementioned studies has analyzed the relationship between inequality and conflict in the DRC, and that we are not aware of any such studies. Nonetheless, the main question is whether it is inequality that causes conflict in the country or vice versa. To answer this question, it is important to understand that according to UNDP (2014) conflict risk factors in the DRC are rooted in long-standing tensions over ethnicity and citizenship rights, which in turn are related to grievances over access to resources, particularly land but also minerals and other natural resources. However, the recent conflict in the country has been particularly fueled by the quest for natural resources and control over informal cross-border trading activities by many actors whose sole motive is the accumulation of personal wealth. Therefore there is room to argue that the ethnicity component has played a less important role in the conflict. Indeed, no dominant or disadvantaged groups, ethnic or otherwise, have been significantly associated with the conflict in the DRC or exclusively engaged in armed conflicts with the central government. This argument can be supported not only on the basis of the empirical evidence above related to cross-cutting, but also by Bates' (2000) argument that ethnic diversity does not imply political violence, especially when it provides a political structure that renders implicit contracts between generations credible. In addition, and also following Bates (2000), none of the largest ethnic groups in the DRC amounts to $50 \%$ or more of the population, so there is no possibility of permanent political homogeny or permanent political exclusion-circumstances under which people may change their preferred form of political action, switching from protest to violence.

In contrast, we argue that the conflict in the DRC has aggravated existing inequalities, especially vertical inequalities, and in turn these inequalities have reinforced the scope of the conflict under cover of natural resource extraction. The situation is thus comparable to the conflicts in Angola, where increasing oil and diamond production during the 1960s and 1970s considerably raised the stakes of conflicts and, together with the war itself, fueled rising inequality (Hodges, 2001). The main channels of conflict in the DRC are poor governance, the weakness of state institutions, 
extreme poverty, youth unemployment, and the political and economic marginalization of the majority of the population; bad governance at the administrative, economic, political, judicial and security levels is characterized by the absence of citizen participation, the failure of parliamentary oversight of government actions, and the disconnection of elected officials from the population they are supposed to represent (UNDP, 2014). To test our argument that conflicts in the DRC have aggravated existing inequalities, we conduct a regression analysis in order to test the effect of conflict after controlling for other factors. A positive significant effect of conflict on horizontal inequality would corroborate our guess.

\subsection{Empirical analysis of the relation between horizontal inequality and conflict}

Figure 2: Map of the second Congo War, 2001-2003

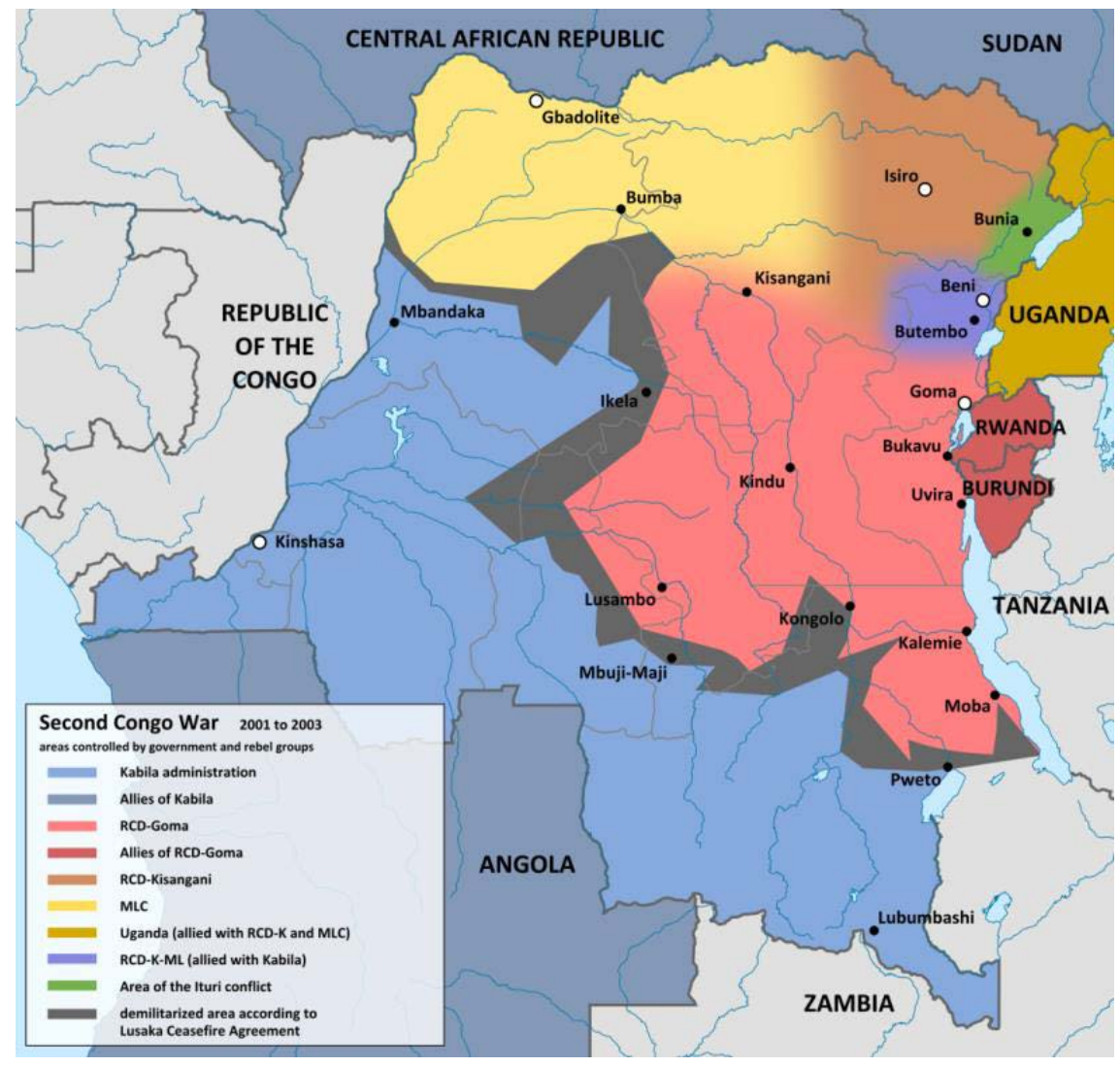

Source: Wikimedia Commons/Don-kun and Uwe Dedering. ${ }^{2}$

In this section we aim to assess the effect of conflict on the extent of and trends in group-based inequality in the DRC. This question is of crucial importance in the country's post-conflict era, and the data at hand cover the period of repeated unforeseen developments in the conflict. Assuming that a relatively long period of conflict can create huge inequalities between conflict and non-conflict zones that can last for many years, we split the country into two zones for the purpose of the analysis, using the map of the second Congo War (see Figure 2). The non-conflict zone is made up of all the territories that were held by the central government (the capital city Kinshasa, Bandundu, Bas-Congo, part of Katanga, Kasai-Occidental, part of Kasai-Oriental and part of

\footnotetext{
${ }^{2}$ https://commons.wikimedia.org/wiki/File:Second_Congo_War_2001_map_en.png
} 
Équateur); the conflict zone is made up of the old districts ${ }^{3}$ and provinces that were held by rebel groups during the second Congo War (Ituri, Sankuru, Haut-Uele, Bas-Uele, Nord-Ubangi, Mongala, Tanganika, and the provinces of Maniema, North Kivu and South Kivu). Using data from the 2007 and 2013 Demographic and Health Surveys, we analyze the determinants of horizontal inequality, especially gender-based inequality in years of education.

\subsection{The model}

We consider the following panel data models for each of the inequality measures:

$$
\begin{gathered}
\operatorname{GGINI}_{i t}=\beta_{0}+\beta_{1} \text { Conflict }+\beta_{2} \text { Wealth }_{i t}+\beta_{3} \text { Hhsize }_{i t}+\beta_{4} \text { Rur }+\beta_{5} Y 2013 \\
+\varepsilon_{i t} \\
\operatorname{GCOV}_{i t}=\beta_{0}+\beta_{1} \text { Conflict }+\beta_{2} \text { Wealth }_{i t}+\beta_{3} \text { Hhsize }_{i t}+\beta_{4} \text { Rur }+\beta_{5} Y 2013+\varepsilon_{i t}
\end{gathered}
$$

where Conflict is a dummy variable that takes on the value 1 for parts of the country that were affected by conflicts and 0 otherwise; Rur is a dummy variable that takes on the value 1 for rural areas and 0 otherwise; $Y 2013$ is a dummy variable that takes on the value 1 for the year 2013 and 0 otherwise; Wealth $_{i t}$ is the wealth index for a given zone $i$ in year $t$; and $H h$ size $_{i t}$ is the average

\begin{tabular}{|c|c|c|c|c|c|}
\hline \multirow{2}{*}{\multicolumn{2}{|c|}{ Variable }} & \multicolumn{2}{|c|}{ GGINI equation } & \multicolumn{2}{|c|}{ GCOV equation } \\
\hline & & (1) & (2) & (3) & (4) \\
\hline \multirow{2}{*}{\multicolumn{2}{|c|}{ Conflict }} & & $0.069^{\star \star \star}$ & & $0.174^{\star \star \star}$ \\
\hline & & & $(0.000)$ & & $(0.009)$ \\
\hline \multirow{2}{*}{\multicolumn{2}{|c|}{ Wealth }} & $-0.058^{\star \star \star}$ & $-0.046^{\star \star \star}$ & $-0.142^{\star \star \star}$ & $-0.114^{\star \star \star}$ \\
\hline & & $(0.000)$ & $(0.000)$ & $(0.000)$ & $(0.000)$ \\
\hline \multirow{2}{*}{\multicolumn{2}{|c|}{ Household size }} & $0.031^{\star \star \star}$ & $0.019 * \star \star$ & $0.068^{\star \star \star}$ & $0.038^{* * *}$ \\
\hline & & $(0.000)$ & $(0.000)$ & $(0.000)$ & $(0.004)$ \\
\hline \multirow{2}{*}{\multicolumn{2}{|c|}{ Rural areas }} & $0.068^{\star * \star}$ & $0.060 * \star *$ & $0.117^{\star \star}$ & $0.073^{\star \star}$ \\
\hline & & $(0.000)$ & $(0.000)$ & $(0.017)$ & $(0.023)$ \\
\hline \multirow{2}{*}{\multicolumn{2}{|c|}{ Year 2013}} & $-0.102^{\star \star \star}$ & $-0.061^{\star \star \star}$ & $-0.061^{\star \star \star}$ & $-0.157^{\star \star \star}$ \\
\hline & & $(0.000)$ & $(0.003)$ & $(0.000)$ & $(0.009)$ \\
\hline \multirow{2}{*}{\multicolumn{2}{|c|}{ Constant }} & -0.013 & 0.012 & 0.012 & 0.065 \\
\hline & & $(0.807)$ & $(0.770)$ & $(0.977)$ & $(0.538)$ \\
\hline & Within & 0.7367 & 0.7973 & 0.7369 & 0.7964 \\
\hline & Between & 0.6726 & 0.7492 & 0.5562 & 0.6509 \\
\hline & Overall & 0.7044 & 0.7731 & 0.6580 & 0.7327 \\
\hline \multicolumn{2}{|c|}{ Prob(Chi2) } & 0.000 & 0.000 & 0.000 & 0.000 \\
\hline \multicolumn{2}{|c|}{ Observations } & 62 & 62 & 62 & 62 \\
\hline
\end{tabular}
size of household in region $i$ in year $t$.

Table 9: Heteroskedasticity-robust estimation of the inequality equation

Source: author's computation.

Our sample is made up of 31 geographical entities over the two periods (2007 and 2013), which allows us to use 62 observations in the analysis. The two years were considered as they relate to the same survey, ensuring the same methodology of data collection. In addition, the chosen period is of interest as it characterizes the post-conflict period, during which the government implemented various policy reforms in order to boost economic growth and mitigate the effect of

\footnotetext{
${ }^{3}$ Old districts have now been turned into provinces.
} 
conflicts. More importantly, this choice allows us to learn whether the implemented policies have had any significant effect on horizontal inequality.

To achieve this, a dummy variable (Y2013) is included to account for trends in horizontal inequality in education. Reported in Table 9 is the heteroskedasticity-robust estimation of equations [1] and [2] with random effects. Globally, all the factors are statistically highly significant determinants of gender-based inequality in years of formal education, as all the estimated coefficients are statistically significant in both estimated equations. The significant coefficients are so at the $1 \%$ significant level, except the coefficient of $R u r$ in the GCOV equation. The independent variables included in the regression explain more that $65 \%$ of the variations in the observed horizontal inequality when the conflict variable is not included in the model, and more than $73 \%$ when the conflict variable is accounted for.

Three facts are worth mentioning. First, an increase in the size of household above the average household size leads to an increase in gender-based inequality in education. Second, gender-based horizontal inequality in education decreases with the improved economic status of households, as proxied by the wealth index. Third, the level of gender-based inequality in years of education was lower in 2013 compared with 2007. Finally, gender-based inequality in years of formal education is higher in conflict-affected areas than in non-affected areas. The estimated models show that gender-based inequality in years of education is 0.069 points higher in conflict-affected areas based on the GGINI index, and 0.174 points higher based on the GCOV index.

\section{Conclusion}

The aim of this paper was to analyze the extent of and trends in group-based inequality in the DRC in comparison with the trend in vertical inequality. To achieve this objective, we used data from five surveys conducted between 2001 and 2013 in the categories of Demographic and Health Surveys, Multiple Indicator Cluster Surveys, and Consumption and Expenditure Surveys. To operationalize our objective, we calculated group-weighted inequality measures (GGINI, GTHEIL and GCOV) and conducted a regression analysis in order to identify the significant determinants of gender-based horizontal inequality in years of education, using the data for 2007 and 2013. The measures of horizontal inequality were complemented by measures of crosscuttingness and cross-fractionalization.

The main finding is that horizontal inequality followed the same trend as vertical inequality over the period of analysis. Vertical inequality in years of education increased between 2001 and 2007, then decreased between 2007 and 2010, but was been on the increase after 2010. However, a different trend was observed in vertical inequality in economic status: it decreased between 2001 and 2007, and increased between 2007 and 2013. For example, the Gini coefficient of education increased from 0.30 in 2001 to 0.47 in 2007, then decreased from its 2007 level to 0.39 in 2013. The Gini coefficient for wealth decreased from 0.64 in 2001 to 0.39 in 2007, and then increased to 0.41 in 2010 and 0.49 in 2013.

Horizontal inequality along different dimensions of ethnic diversity (ethnic groups, religion, region, geographical area, language) followed the same trend as that observed for vertical inequality for both socio-economic variables (years of education and wealth). It is important to note that the levels of horizontal inequality in economic status, as measured by the wealth index, are higher among geographical areas, especially among administrative regions and between rural and urban areas. In contrast, lower levels of horizontal inequality were observed among religions and among ethnic groups. On the other hand, the analysis of horizontal inequality in years of formal education 
shows that geographical, gender and linguistic inequalities are more important than those observed among religions and ethnic groups. In addition, horizontal inequality between males and females is higher among individuals aged 25 and over compared with the level observed in the full sample of individuals aged 15 years and over for a particular year.

The regression analysis of the determinants of horizontal inequality indicates that household size, economic status and rural residence have a highly significant effect on gender-based inequality in years of education. While larger size of household and rural residence increase gender-based horizontal inequality in education, improved economic status through higher levels of wealth decreases its extent. Moreover, the results confirm the decreasing trend in horizontal inequality between 2007 and 2013. Finally, there exists a significant relation between gender-based horizontal inequality in years of education and conflict. The estimated effect is positive and highly significant, showing that the conflict has aggravated existing inequalities.

These findings are important for informing the kinds of action to be undertaken in order to achieve sustainable development goals with fairness from the group perspective. To this end, there is a need to identify persistent group-specific characteristics, as well as factors that reinforce differences between groups and constrain the implementation of a fairer society in the DRC from the perspective of groups in general and more equitable groups within identified cleavages in particular. These are factors on which policies can efficiently act in order to reduce and reverse the direction of growing group-based inequalities in both economic status and years of education. The focus must then be on gender-specific issues that constrain the economic and educational empowerment of women within and across different cleavages, as well as specific factors pertaining to the rural-urban gap in terms of access to assets, public service utilities and the formal educational system.

\section{References}

Alesina, A., Baqir, R. and Easterly, W. (1999). Public goods and ethnic divisions. Quarterly Journal of Economics 114: 1243-1284.

Alesina, A., Devleeschauwer, A., Easterly W., Kurlat, S. and Wacziarg, R. (2003). Fractionalization. Journal of Economic Growth 8(2): 155-194.

Alesina, A. and Perotti, R. (1996). Income distribution, political instability and investment. European Economic Review 40(6): 1203-1228.

Bates, R.H. (2000). Ethnicity and development in Africa: a reappraisal. AER Papers and Proceedings 90(2): 131-134.

Collier, P. (2000). Doing well out of war: an economic perspective. In: Greed and Grievance: Economic Agendas in Civil Wars, M. Berdal and D.M. Malone (eds). IDRC/Lynne Rienner: Boulder and London.

Collier, P. and Hoeffler, A. (1996). On economic causes of civil war. Mimeo. Center for the Study of African Economies: Oxford.

Collier, P. and Hoeffler, A. (1998). On economic causes of civil war. Euconomic Papers 50: 463-573.

Collier, P. and Hoeffler, A. (2004). Greed and grievance in civil war. Oxford Economic Papers 56: 563-595.

Cramer, C. (2003). Does inequality cause conflict? Journal of International Development 15: 397-412. 
Davidson, B. (1992). The Black Man's Burden: Africa and the Curse of the Nation-State. Times Books: New York.

Easterly, W. and Levine, R. (1997). Africa's growth tragedy: policies and ethnic divisions. Quarterly Journal of Economics 112(4): 1203-1250.

Esteban, S.L. and Ray, D. (1999). Conflict and distribution. Journal of Economic Theory 87(2): 379_ 415.

Esteban, J. and Ray, D. (2008). On the salience of ethnic conflict. American Economic Review 98(5): 2185-2202.

Fearon, J. and Laitin, D. (2003). Ethnicity, insurgency and civil war. American Political Science Review 97(1): 75-90.

Gubler, R. and Selway, J.S (2012). Horizontal inequality, crosscutting cleavages and civil war. Journal of Conflict Resolution 56(2): 206-232.

Hodges, T. (2001). Angola from Afro-Diamond to Petro-Diamond Capitalism. James Currey: Oxford, and Indiana University Press: Bloomington.

Humphreys, M. and Weinstein, J.M. (2008). Who fights? The determinants of participation in civil war. American Journal of Political Science 52(2): 436-455.

INS (2014). Enquête sur l'emploi et la consommation des ménages. Institut National de la Statistique: Kinshasa.

Kaplan, R. (1994). The coming anarchy. Atlantic Monthly 73(2): 44-76.

Matuszeski, J. and Schneider, F. (2006). Patterns of ethnic group segregation and civil conflict. Working paper. University of Harvard: Cambridge.

Mauro, P. (1995) Corruption and growth. Quarterly Journal of Economics 110: 681-712.

Montalvo, J. and Reynal-Querol, M. (2005). Ethnic polarization, potential conflict, and civil wars. American Economic Review 95(3): 796-816.

Montalvo, J.G. and Reynal-Querol, M. (2008) Discrete polarization with an application to the determinants of genocides. Economic Journal 118: 1835-1865.

Moummi, A. (2010) Analyse de la pauvreté en République Démocratique du Congo. AfDB Working Papers Series 112. African Development Bank Group: Abidjan.

Muller, E.N. and Seligson, M.A. (1987). Inequality and insurgency. American Political Science Review 81(2): 425-451.

Murshed, S. and Gates, S. (2005). Spatial-horizontal inequality and the Maoist insurgency in Nepal. Review of Development Economics 9(1): 121-134.

Nafziger, E.W. and Auvinen, J. (1997). War, hunger and development: an econometric investigation into the sources of humanitarian emergencies. Working Paper 142. UNUWIDER: Helsinki.

Nafziger, E.W. and Auvinen, J. (2002). Economic development, inequality, war, and state of violence. World Development 30(2): 153-163.

Noyoo, N. (2000). Ethnicity and development in sub-Saharan Africa. Journal of Social Development in Africa 15(2): 55-67.

Ortiz, I. and Cummins, M. (2011). Global inequality: beyond the bottom billion-a rapid review of income distributions in 141 countries. UNICEF Social and Economic Working Papers. UNICEF: New York. 
Robinson, J.A. (2001). Social identity, inequality and conflict. Economics of Governance 2(1): 85-99.

Sahn, D.E. and Stifel, D.C. (2000). Poverty comparisons over time and across countries in Africa. World Development 28(12): 2123-2155.

Schatzberg, M.G. (1981). 'Ethnicity and Class at the Local Level: Bars and Bureaucrats in Lisala, Zaire'. Comparative Politics, 13(4): 461-78.

Selway, J.S. (2011). The measurement of cross-cutting cleavages and other multidimensional cleavage structures. Political Analysis 19(1): 48-65.

Shapiro, D. and Tambashe, B.O. (1999). Gender, poverty and school enrollment in Kinshasa, Congo. In: Third African Population Conference, Durban, South Africa, 6-10 December 1999: The African Population in the 21st Century, Volume III, Union for African Population Studies (ed.). UAPS: Accra.

Stewart, F. (2000). Crisis prevention: tackling horizontal inequalities. Working Paper 33. University of Oxford: Oxford.

Stewart, F. (2002). Horizontal inequality: a neglected dimension of development. UNU-WIDER Annual Development Lecture: Helsinki.

Stewart, F., Brown, G. and Mancini, L. (2010). Monitoring and measuring horizontal inequalities. Centre for Research on Inequality, Human Security and Ethnicity: Oxford.

Taylor, C. and Hudson, M. (1972). World Handbook of Political and Social Indicators, Second Edition. Yale University Press: New Haven.

UNDP (2014). Building peace and advancing development in the Great Lakes Region. UNDP: New York. 